\title{
Unexpected reduction of the nitro group in (3-nitrophenyl)-1,2,4-triazines during their aza-Diels-Alder reaction with 1-morpholinocyclopentene
}

\author{
Dmitry S. Kopchuk, ${ }^{* a, b}$ Albert F. Khasanov, ${ }^{a}$ Igor S. Kovalev, ${ }^{a}$ \\ Grigory V. Zyryanov, ${ }^{a, b}$ Vladimir L. Rusinov $^{a, b}$ and Oleg N. Chupakhin ${ }^{a, b}$ \\ a Department of Organic Chemistry, Ural Federal University, 620002 Ekaterinburg, Russian Federation \\ ${ }^{b}$ I. Ya. Postovsky Institute of Organic Synthesis, Ural Branch of the Russian Academy of Sciences, \\ 620990 Ekaterinburg, Russian Federation.Fax: +7343 374 1189; e-mail: dkopchuk@mail.ru
}

DOI: 10.1016/j.mencom.2013.07.010

Unexpected reduction of the nitro group to the amino one during aza-Diels-Alder reaction between (3-nitrophenyl)-1,2,4-triazines and 1-morpholinocyclopentene (neat, $200^{\circ} \mathrm{C}$, argon) occurred to furnish 4-(3-aminophenyl)-6,7-dihydro-5H-cyclopenta[c]pyridines.

Aminophenyl-containing pyridines are of interest for their further functionalization leading to new heterocyclic systems. ${ }^{1}$ Moreover, they possess biological activity. ${ }^{2}$

On the other hand, 2-(het)arylpyridines are common ligands for various metal cations, some of them having found use as phosphorescent labels for bioimaging. ${ }^{3}$ Aminoaryl-substituted derivatives of 2-(het)arylpyridines are good substrates for this purpose, as they can be readily converted into isothiocyanate ones by treatment with thiophosgene just before the bioconjugation. ${ }^{4}$ For the effective bioimaging these functional groups are usually separated from the metal chelating site, e.g., by aromatic substituent(s).

A number of methods for the synthesis of aminophenylpyridines are described in literature. ${ }^{5,6}$ However, only one example based on 1,2,4-triazine methodology for the synthesis of aminophenyl-containing pyridine ${ }^{7}$ is described, although this approach has been recognized as a prospective tool to access various pyridines. ${ }^{8}$ The key advantage of this methodology is the possibility for one-step derivatization of $\mathrm{C} 3$ and/or $\mathrm{C} 4$ positions in newly formed pyridine ring simply by varying the dienophile and/or the the substitution pattern in the starting 1,2,4-triazines. Herein, we describe an application of this methodology to access aminophenyl-containing pyridines.

2-(Het)arylpyridines bearing aminophenyl substituent at C5 position were the targets of our study since cyclometalled complexes of similar ligands possess an intriguing photophysical properties, ${ }^{9}$ therefore these complexes can be promising chromophores for the photoluminescent imaging of biomolecules. In addition, the phosphorescent label based on platinum complex of similar ligand containing carboxylic group for further conjugation with biomolecule was reported. ${ }^{10}$

For the synthesis of parent 1,2,4-triazines two previously described methods were used. ${ }^{11}$ Interaction of 2-bromo-3'-nitroacetophenone $\mathbf{1}$ with two equivalents of carboxhydrazides 2 or condensation of isonitrosoacetophenone hydrazones $\mathbf{3}$ with pyridine-2-carboxaldehyde $\mathbf{4}$ afforded triazines $\mathbf{5 a - e}$ (Scheme 1, for details, see Online Supplementary Materials).

Comparative studies of photophysical properties of platinum complexes of 5-aryl-2-(2-thienyl)pyridines and the corresponding cyclopenteno[ $c]$ pyridines demonstrated that the latter exhibit higher values for both the luminescence lifetime and quantum yield, ${ }^{9(a)}$ therefore they are more preferable for application as phosphorescent labels for bioimaging. To obtain cyclopenteno$[c]$ pyridines from 1,2,4-triazines 5, 1-morpholinocyclopentene should be used as the dienophile in the aza-Diels-Alder reaction.

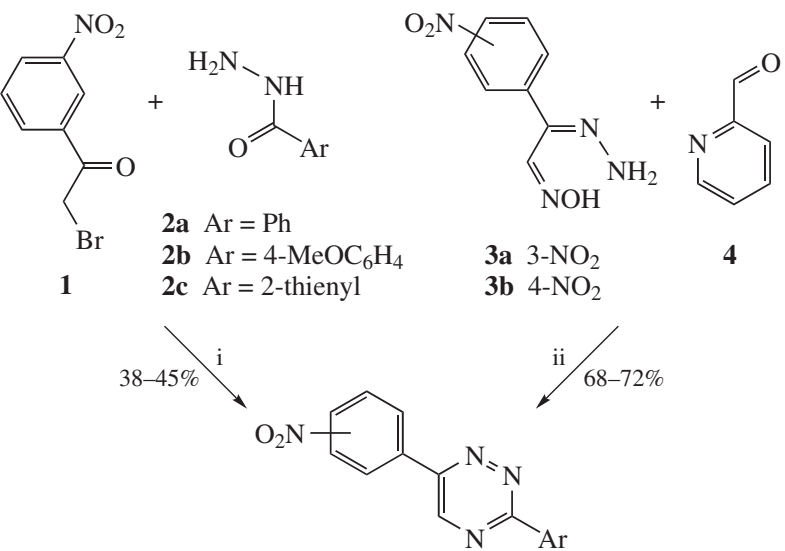

$$
\begin{aligned}
& \text { 5a } 3-\mathrm{NO}_{2}, \mathrm{Ar}=\mathrm{Ph} \\
& \text { 5b } 3-\mathrm{NO}_{2}, \mathrm{Ar}=4-\mathrm{MeOC}_{6} \mathrm{H}_{4} \\
& \text { 5c } 3-\mathrm{NO}_{2}, \mathrm{Ar}=2 \text {-thienyl } \\
& \text { 5d } 3-\mathrm{NO}_{2}, \mathrm{Ar}=2 \text {-pyridyl } \\
& \text { 5e } 4-\mathrm{NO}_{2}, \mathrm{Ar}=2 \text {-pyridyl }
\end{aligned}
$$

Scheme 1 Reagents and conditions: i, AcONa, EtOH-AcOH $(3: 1), 105^{\circ} \mathrm{C}$, $12 \mathrm{~h}$; ii, ethanol, $20^{\circ} \mathrm{C}, 10 \mathrm{~h}$, then $\mathrm{AcOH}, 118^{\circ} \mathrm{C}, 5 \mathrm{~min}$.

The target cyclopenteno[c]pyridines $\mathbf{6}$ were prepared as described $^{12}$ by heating 1,2,4-triazines $\mathbf{5 a - d}$ with an excess of enamine at $200{ }^{\circ} \mathrm{C}$ without solvent under argon atmosphere. Unexpectedly, the processing not only led to the complete formation of the cyclopentenopyridine system, but also caused the reduction of nitro group into the amino one (Scheme 2 ). ${ }^{\dagger}$ It should be noted that for the full conversion of $\mathbf{5}$, longer reaction time compared to the original procedure was required.

\footnotetext{
Synthesis of 6,7-dihydro-5H-cyclopenteno[c]pyridines 6, 9 and $\mathbf{1 0}$ (typical procedure). Mixture of corresponding triazine 5,7 or $8(2 \mathrm{mmol})$ and 1-morpholinocyclopentene $(1.6 \mathrm{ml}, 10 \mathrm{mmol})$ was stirred at $200^{\circ} \mathrm{C}$ under argon atmosphere for $2 \mathrm{~h}$, after that two more portions of enamine $(2 \times 0.64 \mathrm{ml}, 2 \times 4 \mathrm{mmol})$ were added and the reaction mixture was stirred at $200^{\circ} \mathrm{C}$ for $1 \mathrm{~h}$ after each portion. The mixture was cooled to room temperature and placed as is on chromatographic column $\left(\mathrm{SiO}_{2}\right)$ and eluted with chloroform. Combined fractions containing product $\left(R_{\mathrm{f}}=0.2\right)$ were concentrated under reduced pressure to $c a .10 \mathrm{ml}$. The product was extracted with $3 \mathrm{~N}$ hydrochloric acid $(3 \times 20 \mathrm{ml})$. Sodium hydroxide pellets were added to hydrochloric acid extract upon cooling to adjust $\mathrm{pH}$ to 12 and the product was extracted with dichloromethane $(3 \times 20 \mathrm{ml})$. The combined organic extracts were dried with anhydrous sodium sulfate, filtered and solvent was removed under reduced pressure. Analytical sample was recrystallized from ethanol.
} 
<smiles>O=[N+]([O-])c1cccc(-c2cnc([Al])nn2)c1</smiles>
5a-d<smiles>Nc1cccc(-c2cnc(Br)c3c2CCC3)c1</smiles>

6a $\mathrm{Ar}=\mathrm{Ph}, 55 \%$

6b $\mathrm{Ar}=4-\mathrm{MeOC}_{6} \mathrm{H}_{4}, 54 \%$

6c $\mathrm{Ar}=2$-thienyl, $50 \%$

6d $\mathrm{Ar}=2$-pyridyl, $45 \%$

Scheme 2 Conditions: i, neat, $200^{\circ} \mathrm{C}$, argon atmosphere, $4 \mathrm{~h}$.

Structures of products 6 were proved by ${ }^{1} \mathrm{H}$ and ${ }^{13} \mathrm{C}$ NMR data (a significant upfield shift of signals of hydrogen atoms of phenyl ring was observed). The presence of amino group in compounds 6 was confirmed by $2 \mathrm{D} \operatorname{COSY}\left({ }^{1} \mathrm{H}-{ }^{15} \mathrm{~N}\right)$ experiment carried out for product $\mathbf{6 c}$. Thus, the interaction between nitrogen atom (54 ppm) and hydrogen atoms (3.78 ppm) was observed in 2D COSY $\left({ }^{1} \mathrm{H}-{ }^{15} \mathrm{~N}\right)$ spectra.

Interestingly, isomeric 4-nitrophenyl-1,2,4-triazine 5e gave neither nitro- nor aminophenyl-substituted cyclopenteno[c]pyridine $6 \mathbf{e}$ and only a complex mixture of unidentified products was formed (Scheme 3).
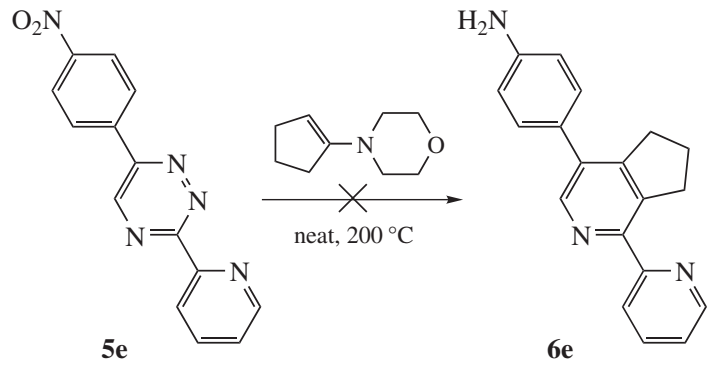

Scheme 3

4-(3-Aminophenyl)-1-phenyl-6,7-dihydro-5H-cyclopenteno[c]pyridine 6a. Yield $315 \mathrm{mg}(1.1 \mathrm{mmol}, 55 \%), \mathrm{mp} 144-146^{\circ} \mathrm{C} .{ }^{1} \mathrm{H} \mathrm{NMR}\left(\mathrm{CDCl}_{3}\right)$ $\delta: 2.08\left(\mathrm{~m}, 2 \mathrm{H}, 6-\mathrm{CH}_{2}\right), 3.06\left(\mathrm{t}, 2 \mathrm{H}, 7-\mathrm{CH}_{2},{ }^{3} \mathrm{~J} 7.2 \mathrm{~Hz}\right), 3.17(\mathrm{t}, 2 \mathrm{H}$, 5- $\mathrm{CH}_{2},{ }^{3} \mathrm{~J} 7.2 \mathrm{~Hz}$ ), 3.78 (br. s, $2 \mathrm{H}, \mathrm{NH}_{2}$ ), 6.73 [m, 1H, H-4 (3- $\mathrm{NH}_{2} \mathrm{Ph}$ )],

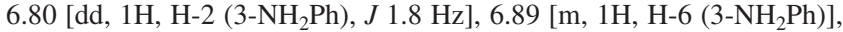
7.26 [dd, 1H, H-5 (3-NH $\left.{ }_{2} \mathrm{Ph}\right), J 8.0 \mathrm{~Hz}$ ], $7.41(\mathrm{~m}, 1 \mathrm{H}, \mathrm{Ph}), 7.48(\mathrm{~m}, 2 \mathrm{H}$, $\mathrm{Ph}), 7.79$ ( $\mathrm{m}, 2 \mathrm{H}, \mathrm{Ph}), 8.54$ (s, 1H, H-3). ${ }^{13} \mathrm{C} \mathrm{NMR}\left(\mathrm{CDCl}_{3}\right) \delta: 25.9$, 33.0, 33.1, 114.4, 115.1, 119.0, 128.2, 128.3, 128.5, 129.5, 132.8, 137.4, 139.0, 140.1, 146.7, 147.1, 152.5, 152.8. ESI-MS, $m / z: 287.16(\mathrm{M}+\mathrm{H})^{+}$ (required 287.15). Found (\%): C, 83.60; H, 6.27; N, 9.69. Calc. for $\mathrm{C}_{20} \mathrm{H}_{18} \mathrm{~N}_{2}$ (\%): C, 83.88; H, 6.34; N, 9.78.

3-(3-Aminophenyl)-1-(2-pyridyl)-6,7-dihydro-5H-cyclopenteno[c]pyridine 9. Yield $270 \mathrm{mg}(0.94 \mathrm{mmol}, 47 \%), \mathrm{mp} 108-110{ }^{\circ} \mathrm{C} .{ }^{1} \mathrm{H} \mathrm{NMR}$ $\left(\mathrm{CDCl}_{3}\right) \delta: 2.13\left(\mathrm{~m}, 2 \mathrm{H}, 6-\mathrm{CH}_{2}\right), 3.00\left(\mathrm{t}, 2 \mathrm{H}, 7-\mathrm{CH}_{2}, J 7.6 \mathrm{~Hz}\right), 3.45(\mathrm{t}$, $2 \mathrm{H}, 5-\mathrm{CH}_{2}, J 7.2 \mathrm{~Hz}$ ), 3.75 (br. s, $2 \mathrm{H}, \mathrm{NH}_{2}$ ), 6.73 [m, 1H, H-4 (3- $\mathrm{NH}_{2} \mathrm{Ph}$ )], 7.26 [m, 2 H, H-5 (3-NH $\left.{ }_{2} \mathrm{Ph}\right), \mathrm{H}-5$ (Py)], 7.45 [m, 1H, H-6 (3- $\left.\left.\mathrm{NH}_{2} \mathrm{Ph}\right)\right]$, 7.51 [dd, 1H, H-2 (3- $\left.\mathrm{NH}_{2} \mathrm{Ph}\right), J 2.0 \mathrm{~Hz}$ ], 7.63 (s, 1H, H-4), 7.81 [ddd, 1H, $\mathrm{H}-4$ (Py), J 7.8, 7.8 and $2.0 \mathrm{~Hz}$ ], 8.43 [dd, 1H, H-3 (Py), J 7.8 and $1.0 \mathrm{~Hz}$ ], 8.69 [dd, 1H, H-6 (Py), J 4.8 and $2.0 \mathrm{~Hz}$ ]. ${ }^{13} \mathrm{C} \mathrm{NMR}\left(\mathrm{CDCl}_{3}\right) \delta: 25.1$, $32.8,33.0,113.8,115.4,116.6,117.3,122.7,123.2,129.5,136.3,138.0$, 141.0, 146.8, 148.4, 151.2, 154.6, 156.7, 158.8. ESI-MS, $m / z: 288.15$ $(\mathrm{M}+\mathrm{H})^{+}($required 288.15). Found (\%): C, 79.22; H, 5.80; N, 14.72. Calc. for $\mathrm{C}_{19} \mathrm{H}_{17} \mathrm{~N}_{3}(\%)$ : C, 79.41; H, 5.96; N, 14.62 .

For synthesis of compounds $\mathbf{5}, \mathbf{7}$ and $\mathbf{8}$ and characteristics of compounds 6b-d, 7, 8 and 10, see Online Supplementary Materials.<smiles>O=CC(=O)c1cccc([N+](=O)[O-])c1</smiles><smiles>N=C(NN)c1ccccn1</smiles><smiles>CC#CC</smiles>

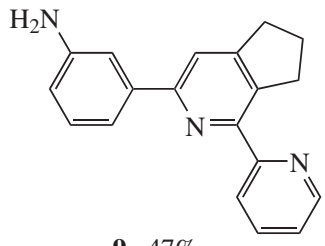

9, $47 \%$
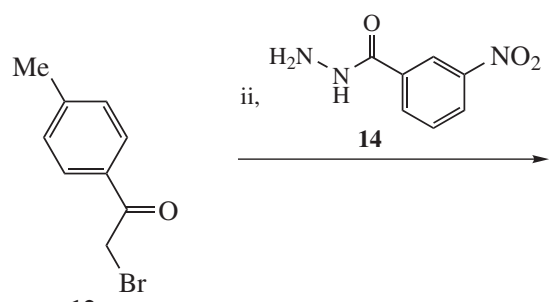

12

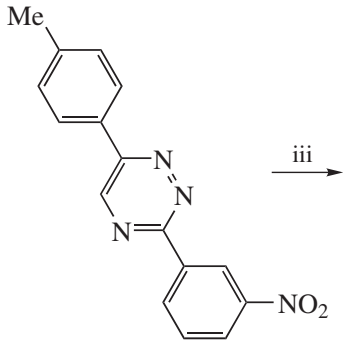

8

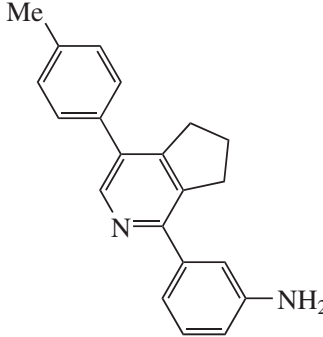

10, $52 \%$

Scheme 4 Reagents and conditions: i, ethanol, $78^{\circ} \mathrm{C}, 2 \mathrm{~h}$; ii, ethanol-AcOH (3:1), $90^{\circ} \mathrm{C}$, argon atmosphere, $10 \mathrm{~h}$; iii, 1-morpholinocyclopentene, neat, $200^{\circ} \mathrm{C}$, $\arg$ on atmosphere, $4 \mathrm{~h}$.

In order to investigate the influence of the position of 3-nitrophenyl substituent onto the reaction outcome we tested other 3-nitrophenyl-substituted 1,2,4-triazines ${ }^{11(a), 13} \mathbf{7}$ and $\mathbf{8}$, which gave amino pyridines $\mathbf{9}$ and $\mathbf{1 0}$ in satisfactory yields (Scheme 4). ${ }^{\dagger}$

Presumably enamine acts as a reducing agent in this transformation, with the inert atmosphere being an essential factor. Mechanism of the reaction is under study. Some literature data ${ }^{14}$ support our hypothesis, i.e. the reaction of 2,6-bis[6-(4-nitrophenyl)-1,2,4-triazin-3-yl]pyridine with excess of enamine in boiling 1,4-dioxane in air occurred only as a 1,2,4-triazine-topyridine transformation with nitro group remaining untouched. Refluxing of nitrobenzenes in neat 1-pyrrolidinocyclohexene (more powerful reducing agent) caused the complete reduction of the nitro group. Position of the nitro group in the aromatic substituent in 1,2,4-triazine system is also important. In particular, in case of 4-nitrophenyl-1,2,4-triazines (e.g., 5e) no 4-aminophenylpyridines were isolated. Such a low reactivity can be explained by the conjugation between nitro group and 1,2,4-triazine system as an electron-withdrawing substituent. Apparently, in case of 3-nitrophenyl substituent conjugation between nitro group and 1,2,4-triazine core is weaker.

In conclusion, we have suggested a good method for the conversion of 3-nitrophenyl-substituted 1,2,4-triazines into aryl6,7-dihydro- $5 H$-cyclopenteno[ $c]$ pyridines $\mathbf{6 a - d , ~ 9 , ~} 10$ bearing 3 -aminophenyl moiety, which seems promising for their further conjugation with biomolecules. This method is advantageous in view of the little number of steps and simplicity of the processing. 
This work was supported by the Russian Ministry of Education and Science (state contract nos. 14.740.11.1020 and 14.A18.21.0817), Russian Foundation for Basic Research (grant no. 12-03-31726) and the Council for grants of the President of Russian Federation (grant no. MK-1511.2013.3).

\section{Online Supplementary Materials}

Supplementary data associated with this article can be found in the online version at doi:10.1016/j.mencom.2013.07.010.

\section{References}

1 P. M. Carabateas, P. R. Brundage, K. O. Gelotte, M. D. Gruett, R. R. Lorenz, C. J. Opalka, B. Singh, W. H. Thielking, G. L. Willians and G. Y. Lesher, J. Heterocycl. Chem., 1984, 21, 1857.

2 (a) J. Aebi, A. Binggeli, L. Green, G. Hartmann, H. P. Maerki, P. Mattei, F. Ricklin and O. Roche, Patent US2010/0016282 A1 (Chem. Abstr., 2010, 152, 192176); (b) T. Lene and L. Janus, Patent WO2004087137 (Chem. Abstr., 2004, 141, 314334); (c) S. W. Wright, A. A. Carlo, M. D. Carty, D. E. Danley, D. L. Hageman, G. A. Karam, C. B. Levy, M. N. Mansour, A. M. Mathiowetz, L. D. McClure, N. B. Nestor, R. K. McPherson, J. Pandit, L. R. Pustilnik, G. K. Schulte, W. C. Soeller, J. L. Treadway, I.-K. Wang and P. H. Bauer, J. Med. Chem., 2002, 45, 3865 .

3 (a) Z. Lui, Z. Bian and C. Huang, Top. Organomet. Chem., 2010, 28, 113 ; (b) K. K.-W. Lo, K. Y. Zhang and S. P.-Y. Li, Pure Appl. Chem., 2011, 83, 823; (c) K. K.-W. Lo, W.-K. Hui, C.-K. Chung, K. H.-K. Tsang, D. C.-M. Ng, N. Zhu and K.-K. Cheung, Coord. Chem. Rev., 2005, 249, 1434; (d) L. Armelao, S. Quici, F. Barigelletti, G. Accorsi, G. Bottaro, M. Cavazzini and E. Tondello, Coord. Chem. Rev., 2010, 254, 487.

4 J. Hovinen and P. M. Guy, Bioconjugate Chem., 2009, 404.

5 (a) F. Calderon, J. Vidal-Mas, J. C. De La Rosa, M. B. Jimenez-Diaz, T. Mulet, S. Prats, J. Solana, F. J. Gamo, E. Fernandez, J. Burrows and M. Witty, ASC Med. Chem. Lett., 2012, 3, 373; (b) D. L. Flynn and P. A. Petillo, Patent WO2006/71940 A2 (Chem. Abstr., 2006, 145, 124558); (c) I. R. Baxendale, C. M. Griffiths-Jones, S. V. Ley and G. K. Tranmer, Chem. Eur. J., 2006, 12, 4407.
6 A. K. Nedeltchev, H. Han and P. K. Bhowmik, J. Polym. Sci., Part A: Polym. Chem., 2010, 48, 4408.

7 A. M. Prokhorov, V. N. Kozhevnikov, D. S. Kopchuk, H. Bernard, N. Le Bris, R. Tripier, H. Handel, B. Köenig and D. N. Kozhevnikov, Tetrahedron, 2011, 67, 597.

8 (a) D. L. Boger, Tetrahedron, 1983, 39, 2869; (b) G. R. Pabst, O. C. Pfüller and J. Sauer, Tetrahedron, 1999, 55, 8045; (c) A. Rykowski, D. Branowska and J. Kielak, Tetrahedron Lett., 2000, 41, 3657; (d) D. N. Kozhevnikov, O. V. Shabunina, D. S. Kopchuk, P. A. Slepukhin and V. N. Kozhevnikov, Tetrahedron Lett., 2006, 47, 7025.

9 (a) D. N. Kozhevnikov, V. N. Kozhevnikov, M. M. Ustinova, A. Santoro, D. W. Bruce, B. Köenig, R. Czerwieniec, T. Fischer, M. Zabel and H. Yersin, Inorg. Chem., 2009, 4179; (b) A. Nobuhiko, S. Chizu and O. Rei, Patent EP1932851 A1 (Chem. Abstr., 2006, 146, 441935); (c) D. Wang, J. Wang, H.-L. Fan, H.-F. Huang, Z.-Z. Chu, X.-C. Gao and D.-C. Zou, Inorg. Chim. Acta, 2011, 370, 340; (d) A. M. Prokhorov, A. Santoro, J. A. G. Williams and D. W. Bruce, Angew. Chem. Int. Ed., 2012, 51, 95.

10 A. F. Suleymanova, D. N. Kozhevnikov and A. M. Prokhorov, Tetrahedron Lett., 2012, 53, 5293.

11 (a) T. V. Saraswathi and V. R. Srinivasan, Tetrahedron Lett., 1971, 12, 2315; (b) V. N. Kozhevnikov, D. N. Kozhevnikov, O. V. Shabunina, V. L. Rusinov and O. N. Chupakhin, Tetrahedron Lett., 2005, 46, 1791.

12 V. N. Kozhevnikov, M. M. Ustinova, P. A. Slepukhin, A. Santoro, D. W. Bruce and D. N. Kozhevnikov, Tetrahedron Lett., 2008, 64, 4096.

13 M. O'Rourke, S. A. Lang Jr. and E. Cohen, J. Med. Chem., 1977, 20, 723.

14 V. N. Kozhevnikov, D. N. Kozhevnikov, O. V. Shabunina, V. L. Rusinov and O. N. Chupakhin, Tetrahedron Lett., 2005, 46, 1521.

15 S. Danishefsky and R. Cavanaugh, Chem. Ind. (London), 1967, 52, 2171.

Received: 8th April 2013; Com. 13/4100 